\title{
Comparison of the Kato-Katz and Helmintex methods for the diagnosis of schistosomiasis in a low-intensity transmission focus in Bandeirantes, Paraná, southern Brazil
}

\author{
Kerlen Caldeira ${ }^{1,3}$, Candida Fagundes Teixeira ${ }^{1}$, \\ Manoela Borges da Silveira', Lucas Castello Costa de Fries' ${ }^{1}$, Juliano Romanzini', \\ Hélio Radke Bittencourt ${ }^{2}$, Carlos Graeff-Teixeira ${ }^{1 /+}$
}

\author{
'Laboratórios de Biologia Parasitária, Faculdade de Biociências e Parasitologia Molecular, Instituto de Pesquisas Biomédicas \\ ${ }^{2}$ Faculdade de Matemática, Pontifícia Universidade Católica do Rio Grande do Sul, Av. Ipiranga 6681, 90619-900 Porto Alegre, RS, Brasil \\ ${ }^{3}$ Centro de Vigilância em Saúde, Secretaria Estadual da Saúde, Porto Alegre, RS, Brasil
}

The diagnosis of schistosomiasis is problematic in low-intensity transmission areas because parasitological methods lack sensitivity and molecular methods are neither widely available nor extensively validated. Helmintex is a method for isolating eggs from large faecal samples. We report preliminary results of a comparative evaluation of the Helmintex and Kato-Katz (KK) methods for the diagnosis of schistosomiasis in a low-intensity transmission area in Bandeirantes, Paraná, southern Brazil. Eggs were detected by both methods in seven patients, whereas only Helmintex yielded positive results in four individuals. The results confirm the previously demonstrated higher sensitivity of the Helmintex method compared with the KK method.

Key words: schistosomiasis - low endemicity - parasitological diagnosis

Improvements in living conditions and the successful implementation of measures to control schistosomiasis have led to reductions in its transmission intensity, prevalence and parasitic burden in several areas (Crompton et al. 2003). These reductions have been detected in recently established foci, such as Esteio, in the southernmost Brazilian state of Rio Grande do Sul. In these areas, classical coproparasitological methods are insufficiently sensitive to reliably detect small numbers of eggs in faeces (Doenhoff et al. 2004). In Esteio, most infected individuals exhibit estimated egg concentrations of $<1$ egg per gram (epg) of faeces (Graeff-Teixeira et al. 2004), which is far below the reliable detection capabilities of most methods. Helmintex is a new method for detecting Schistosoma mansoni eggs in stool samples that has recently been described and evaluated in seeding experiments (Teixeira et al. 2007). It allows the detection of lower egg concentrations than what is possible with conventional methods because it enables the processing of larger stool samples $(30 \mathrm{~g})$.

The objective of this work was to evaluate and compare the performance of the Helmintex and Kato-Katz (KK) methods for the first time in a population study in the schistosomiasis endemic area of Bandeirantes, Paraná (PR), southern Brazil. Eosinophil counts in peripheral blood samples were also evaluated as indicators of infection.

\footnotetext{
Financial support: FAPERGS/DECIT MS (PPSUS), CNPq

+ Corresponding author: graeff.teixeira@gmail.com

Received 14 October 2011

Accepted 29 February 2012
}

Bandeirantes is a municipality in northern PR $\left(23^{\circ} 06^{\prime} 36^{\prime} \mathrm{S} 50^{\circ} 22^{\prime} 03^{\prime \prime} \mathrm{W}\right)$ that covers approximately $446 \mathrm{~km}^{2}$ and has approximately 34,000 inhabitants. The study area, Ouro Verde, was chosen based on the suggestion of the local public health service considering the observation of the active transmission of schistosomiasis, the lack of surveys in the past two years and an expected schistosomiasis prevalence of $15 \%$ in the area. The total population of Ouro Verde was 280 inhabitants at the time of this study.

The houses included in the study area were located along a street east of the PR-436 road, which runs to the east and turns $90^{\circ}$ to the south to reconnect with the PR436 road. Grassy and swampy fields lie at the northeastern and southeastern margins of the area. In the northeast, many snails were observed next to a street corner. A stream formed a small natural pool where children participated in recreational activities. Some individuals provided sporadic and spontaneous reports of fishing and washing (clothes and utensils) in the contaminated stream, undertaken mainly by individuals from the nearby houses. Most of the houses had recently been improved and many had been rebuilt in locations away from the stream. Although the local school is well organised and schistosomiasis is the focus of regular health education projects, many students were observed conducting leisure activities in contaminated streams, which illustrates the complexity of controlling schistosomiasis.

We aimed to obtain blood and faecal samples from 100 individuals in Ouro Verde, excluding children less than one year old. Sampling proceeded from the northern to southern branch of the street because the northern branch was closest to the transmission focus.

After informed consent was obtained from each participant, venous blood was collected and a thin distention was immediately prepared, air dried and fixed with 
methanol. Later, in the laboratory, the blood distension was stained with Giemsa to obtain eosinophil counts. Serum was separated by centrifugation and stored at $10^{\circ} \mathrm{C}$ in the field; it was subsequently stored at $-20^{\circ} \mathrm{C}$ in the laboratory for future analysis. At least one total evacuation from each individual was collected in a 1-L plastic vessel with a lid. Blood and faecal samples were obtained from 77 individuals.

In the field laboratory, each faecal sample was weighed and a sample was separated for the KK thick smear. A measured amount of aqueous $4 \%$ formalin was added to completely cover the faecal material. The mass per millilitre was estimated by dividing the faeces mass by the volume of the formalin solution.

Two thick smears were prepared from each faecal sample according to the instructions of the manufacturer of the Helm Test (Brazil) and original description of the KK method (Katz et al. 1972). After $24 \mathrm{~h}$, the slides were subjected to complete smear screening by two examiners, at least one of whom was skilled. For the Helmintex method, a volume of the faecal homogenised suspension corresponding to $30 \mathrm{~g}$ of faeces was processed as described by Teixeira et al. (2007).

Eggs were detected by both methods in seven individuals $(12,12,30,96,108,174$ and $192 \mathrm{epg})$, whereas only Helmintex detected eggs in four individuals (Table I); egg counting was not performed in sediments produced via Helmintex because part of the material was lost. The kappa estimation (0.75) indicates substantial agreement between the KK and Helmintex methods (Landis \& Koch 1977). Considering the results of both analyses, the estimated prevalence of schistosomiasis was $12.3 \%$ (11/77 individuals). Eosinophilia of $>4 \%$ was detected in 10/11 infected individuals, but was also present in 40/66 non-infected individuals, resulting in a $90.9 \%$ sensitivity, $39.4 \%$ specificity, positive predictive value of $20 \%$ and negative predictive value of $96.3 \%$ (Table II). The present data on blood eosinophilia do not support its controversial proposal as an indicator of $S$. mansoni infection, especially considering its poor specificity (Dawson-Hahn et al. 2010). The absence of eosinophilia may, however, indicates a lower probability of infection, considering its very high negative predictive value $(96.3 \%)$ (Table II).

The difficulty of diagnosing schistosomiasis in areas of low-intensity transmission, such as Esteio, has prompted several efforts to improve the sensitivity of egg detection in stool samples, such as using the Percoll and saline density gradient methods (Eberl et al. 2002, Coelho et al. 2009) or polymerase chain reaction analyses of stool samples (Gomes et al. 2010, Oliveira et al. 2010), in addition to the examination of slides using the KK method or combinations of different methods (Siqueira et al. 2011).

The 714-fold higher stool sample volume examined by the Helmintex method ( $30 \mathrm{~g})$ compared with the 42 $\mathrm{mg} / \mathrm{slide}$ by the KK method explains the higher probability of finding small numbers of eggs with the former method and its much higher expected sensitivity. Increasing the amount of stool examined to improve the sensitivity for schistosomiasis diagnosis was ini-

\section{TABLE I}

Comparison of Helmintex and Kato-Katz (KK) methods for the diagnosis of schistosomiasis in a low-intensity transmission area (Ouro Verde, municipality of Bandeirantes, Paraná, Brazil) in 2006

\begin{tabular}{lccc}
\hline \multicolumn{4}{c}{ Helmintex } \\
\hline KK & Positive & Negative & Total \\
\hline Positive & 7 & 0 & 7 \\
Negative & 4 & 66 & 70 \\
\hline Total & 11 & 66 & 77 \\
\hline
\end{tabular}

TABLE II

Evaluation of blood eosinophilia (\%)

as an indicator for schistosomiasis in comparison with the detection of eggs in faeces

Eggs in faeces

\begin{tabular}{lccc}
\hline Blood eosinophilia & Positive & Negative & Total \\
\hline$>4 \%$ & 10 & 40 & 50 \\
$\leq 4 \%$ & 1 & 26 & 27 \\
\hline Total & 11 & 66 & 77 \\
\hline
\end{tabular}

tially proposed many decades ago (Faust \& Meleney 1924). The Helmintex method is based on a sequence of concentration steps that ends with the isolation of eggs through their interaction with paramagnetic beads in a magnetic field. The present evaluation confirms the superior performance of the Helmintex method, which was demonstrated previously in seeding experiments (Teixeira et al. 2007). This new sensitive method is not meant to replace $\mathrm{KK}$ as the routine diagnostic method for schistosomiasis, even in low-intensity transmission areas. The KK method remains the first option because of its simplicity and low cost, whereas Helmintex analysis would be the final step in a sequential screening algorithm (risk assessment, KK analysis, serology and Helmintex analysis). This sequential combination of methods with increasing sensitivity was originally proposed by Andrews (1935) and may represent the most effective approach to detect low-level infections.

\section{ACKNOWLEDGEMENTS}

To Natal Jataí de Camargo (SES, Paraná), Natália Guerra Silva and the staff at SMS, Bandeirantes, and Antônio Plácido de Carvalho (Public Health Regional Laboratory, Jacarezinho, Paraná), for logistical support during fieldwork, and to the kind and enthusiastic support of the residents and community leaders of Ouro Verde. 


\section{REFERENCES}

Andrews MN 1935. The examination of faeces for the ova of Schistosoma japonicum. Chinese Med J 49: 42-46.

Coelho PMZ, Jurberg AD, Oliveira AA, Katz N 2009. Use of a saline gradient for the diagnosis of schistosomiasis. Mem Inst Oswaldo Cruz 104: 720-723.

Crompton DWT, Engels D, Montresor A, Neira MP, Savioli L 2003. Action starts now to control disease due to schistosomiasis and soil-transmitted helminthiasis. Acta Trop 86: 121-124.

Dawson-Hahn EE, Greenberg SLM, Domachowske JB, Olson BG 2010. Eosinophilia and the seroprevalence of schistosomiasis and strongyloidiasis in newly arrived paediatric refugees: an examination of Centers for Disease Control and Prevention screening guidelines. J Pediatr 156: 1016-1018.

Doenhoff MJ, Chiodini PL, Hamilton JV 2004. Specific and sensitive diagnosis of schistosome infection: can it be done with antibodies? Trends Parasitol 20: 35-39.

Eberl M, al-Sherbiny M, Hagan P, Ljubojevic S, Thomas AW, Wilson RA 2002. A novel and sensitive method to monitor helminth infections by fecal sampling. Acta Trop 83: 183-187.

Faust EC, Meleney HE 1924. Studies on schistosomiasis japonica. Am J Hyg 3: 210-220.

Gomes LI, Marques LHS, Enk MJ, Oliveira MC, Coelho PMZ, Rabello A 2010. Development and evaluation of a sensitive PCR-
ELISA system for detection of Schistosoma infection in faeces. PLoS Negl Trop Dis 4: e664.

Graeff-Teixeira C, Valar C, de Moraes CK, Salvany AM, Brum C de O, Maurer RL, Bem R, Mardini LBLF, Jobim MB, do Amaral RS 2004. The initial epidemiological studies in the low endemicity schistosomiasis area in Esteio, Rio Grande do Sul, the southernmost Brazilian state, 1997 to 2000. Mem Inst Oswaldo Cruz 99 (Suppl. I): 73-78.

Katz N, Chaves A, Pellegrino J 1972. A simple device for quantitative stool thick-smear technique in schistosomiasis mansoni. Rev Inst Med Trop S Paulo 14: 397-400.

Landis JR, Koch GG 1977. The measurement of observer agreement for categorical data. Biometrics 33: 159-174.

Oliveira LMA, Santos HLC, Gonçalves MML, Barreto MGM, Peralta JM 2010. Evaluation of polymerase chain reaction as an additional tool for the diagnosis of low-intensity Schistosoma mansoni infection. Diagn Microbiol Infect Dis 68: 416-421.

Siqueira LMV, Coelho PMZ, de Oliveira AA, Massara CL, Carneiro NF de F, Lima ACL, Enk MJ 2011. Evaluation of two coproscopic techniques for the diagnosis of schistosomiasis in a low-transmission area in the state of Minas Gerais, Brazil. Mem Inst Oswaldo Cruz 106: 844-850.

Teixeira CF, Neuhauss E, Ben R, Romanzini J, Graeff-Teixeira C 2007. Detection of Schistosoma mansoni eggs in faeces through their interaction with paramagnetic beads in a magnetic field. PLoS Negl Trop Dis 1: e73. 